\title{
Research on the Impact of Business Strategy on Knowledge-transfer Merger and Acquisition with Innovation Level as the Mediator Variable
}

\author{
$1^{\text {st }}$ Rongying Zhao \\ School of Information \\ Management, Wuhan University \\ zhaorongying@126.com \\ $4^{\text {th }}$ Zhaoyang Zhang \\ School of Information \\ Management, Wuhan \\ University \\ windboy727@vip.qq.com
}

\author{
$2^{\text {nd }}$ Zhuozhu Liu \\ School of Information \\ Management, Wuhan University \\ liuzhuozhu2727@163.com
}

\author{
$3^{\text {rd }}$ Yibei Cai \\ School of Information \\ Management, Wuhan University \\ bella236@163.com
}

\begin{abstract}
Based on the knowledge-transfer $M \& A$ data of listed companies from 2011 to 2016 in China, this paper use logistic regression and multiple linear regression to construct a mediating effect model to determine whether business strategy is associated with knowledge-transfer $M \& A$ by taking innovation level as a mediator variable. After processing data of prospectors and defenders through strategic scoring, this paper applies logistic regression to examine the impact of Business Strategy on knowledge-transfer $M \& A$, and applies multiple linear regression to examine the impact of Business Strategy on innovation level and the impact of knowledge-transfer $M \& A$ on innovation level. From data analysis, this paper concludes that Prospectors are more likely to conduct knowledge-transfer $M \& A$ and these companies are more likely to get a higher innovation level. Besides, the Business Strategy exerts influence on knowledge-transfer $M \& A$ by innovation level.
\end{abstract}

\section{Keywords}

Prospector business strategy; Defender business strategy; Innovation level; knowledge-transfer M\&A

\section{Introduction}

China's previous development was "element-driven," and it is now shifting toward "innovation-driven." Previous M\&A market achieves valuation arbitrage by occupying market share and alliance between strong enterprises. With the country's emphasis on economic restructuring and the implementation of a series of new economic policies, the M\&A market will closely follow the country's innovation-driven development path. Merger and acquisition for the purpose of knowledge transfer is a type of knowledge-transfer merger and acquisition (refer as knowledge-transfer M\&A below). Strategy is an important factor that determines the direction of both a country and a company. Miles and Snow $^{[1-2]}(1978,2003)$ detail three viable business strategies that may exist simultaneously within industries-Prospectors, Defenders, and Analyzers. Bentley $^{[3]}$ (2013) quantified the strategy proposed by Miles and Snow (1978, 2003), and measured different strategies by scoring various financial indicators in various industries. This paper focus on impact of prospectors and defenders on knowledge-transfer M\&A and studies which strategy of prospectors and defenders are used when companies conduct knowledge-transfer M\&A. Relying on Miles and Snow (1978, 2003), Bentley (2013), we construct a mediation effect model to examine the impact of business strategy on knowledge-transfer M\&A through the mediator variable innovation level. Our main findings suggest that prospectors are more positively associated with knowledge-transfer M\&A than defender and prospector are more positively associated with innovation level. In addition, we find that, business strategies have direct influence on knowledge-transfer M\&A by the mediator variable innovation level.

\section{Business strategy}


Considering the timeliness of the relationship between business strategy and audit work, Miles and Snow $^{[1-2]}(1978,2003)$ detailed three possible business strategies that are likely to exist in the industry at the same time: prospector business strategy, defender business strategy, and analyzers business strategy.

These strategies are located on a continuum of strategic distributions, one end is prospector business strategy and the other is defender business strategy. Bentley ${ }^{[3]}$ (2013) quantified the strategic classification proposed by Miles and $\operatorname{Snow}^{[1-2]}(1978,2003)$, and measured different strategies by scoring six financial indicators. They are RDS, EMPS, REV, MS, EMPF and CI. These financial indicators are computed using a rolling average over the prior five years(Ittner $\left.{ }^{[4]}, 1997\right)$. The specific explanation of indices and scoring method will be explicated in business strategy composite measure.

Consistent with previous accounting researches, we mainly focus on two distinct strategic orientations at both ends of the strategic continuum: prospector business strategy and defender business strategy.

\section{Knowledge-transfer M\&A}

Laamanen and Autio $^{[4]}$ (1995) define the "technology-driven new acquisitions" as follows: To acquire new knowledge and technology by acquiring the entire target company or most shares of the target company through different means of payment and channels, so as to get the business control of the target company. Knowledge-transfer M\&A can be understood in the comparison with "technology-driven new acquisitions" or the BKT (Based on Knowledge and Technology) M\&A. Bresman et al. ${ }^{[5]}(1995)$ pointed out that the prior purpose of M\&A is to obtain intangible assets, such as knowledge and technology, human resources and brand, and the process of M\&A is actually a knowledge transfer behavior.

Andreas ${ }^{[6]}(2000)$ argued that the purposes of M\&A are mainly two-folded: to achieve scale effect, and to gain knowledge. After completing the knowledge transfer $\mathrm{M} \& \mathrm{~A}$, the acquiring enterprise will acquire valuable knowledge from the acquired enterprise, including intangible assets and patents. Granstrand et al. ${ }^{[7]}(2010)$ conducted a survey of 42 M\&A cases in different countries and scored the importance of the M\&A method adopted by them. They found that the BKT (based on knowledge and technology) M\&A became increasingly valued and adopted over time in developed countries such as the United States and Japan. Knowledge-transfer M\&A can speed up the company's innovation and enable companies to gain support from the outside for innovation and progress. In fact, this kind of merger based on the acquisition of knowledge and technology is just the knowledge-transfer M\&A that this paper studies. Research and analysis have shown that BKT M\&A are adopted by many large companies in the world today, and this merger and acquisition has become the second largest way to acquire external technologies in addition to technical search. Bena \& $\mathrm{Li}^{[8]}(2014)$ considered that it is a common phenomenon to conduct M\&A with the aim of technology and knowledge acquisition. They analyzed the M\&A cases of US listed companies from 1984 to 2006 and found that nearly two-thirds of M\&As were BKT M\&As.

Ahuja and Katila ${ }^{[9]}$ (2001) pointed out that the acquisition of technology that is different from the company's core technology enable the acquiring company to have different perspectives of research and development, thus enhance its own technological innovation capabilities. Ahuja and Katila ${ }^{[9]}$ (2001)'s research is quite representative. They divided acquisitions into technology-driven and nontechnology-driven ones, and studied the influence of M\&A of chemical companies on innovation performance. Through the empirical research on 72 companies, it was found that non-technical driven M\&A have no significant impact on the company's innovation output, while the technology-driven M\&A can positively promote the company's technological innovation.

Combined with previous research, the knowledgetransfer M\&A is defined as the acquisition of leading new knowledge, new technologies, new processes, and new production processes.

\section{Hypothesis development}

\section{Business strategy and knowledge-transfer M\&A}

The realization of M\&A value mainly depends on effective product and market competition strategies (including the formulation and execution of strategies), which can actually be regarded as the application of certain company capabilities (such as strategic capabilities). Knowledge-transfer M\&A will be influenced by companies' strategic orientation, which is the decisive factor that affects financing. Companies with different strategies will have different choices in business model, financing direction and corporate goals. Song ${ }^{[10]}$ (2007) believes that defenders need higher "market connection" capabilities, and if they want to maintain a dominant position in the single product market, they must make changes in the aspects of market and customer needs in advance. That is why expansion and business scope and merges are rare to see 
in such companies. Therefore, choosing a M\&A target based on its own strategy can fundamentally ensure that the target company matches its own strategy.

Wang Huacheng et al. ${ }^{[11]}$ (2016) used the investment data of listed companies in China in 2007-2013 as the research object, and tested the impact of the company strategy on the over-investment by regression analysis. The strategic division of listed companies in this paper cites the strategic models of Miles and Snow ${ }^{[1-2]}$ (1978, 2003) and Bentley ${ }^{[3]}$ (2013), and divides the company strategies into prospectors, defenders, and analyzers. Based on the results of regression analysis, they summarize the relationship between company strategy and over-investment: prospective companies are more likely to over-invest than defensive ones.

Agrawal et al. ${ }^{[12]}$ (1992) investigated 765 mergers and acquisitions and found that within 1-5 years after mergers and acquisitions taking place, both diversified and related (in the same industry) mergers and acquisitions cannot bring long-term extraordinary returns to the acquiring companies. On the contrary, it would bring negative extraordinary profits. Thereby, it is risky to conduct mergers and acquisitions, especially the knowledge-transfer type, since new knowledge and technologies acquired may not be converted into profits. In this case, prospectors are more willing to take on this risk than the defenders.

In summary, we expect that prospectors are more likely than defenders to engage in knowledge-transfer M\&A. Stated formally:

Hypothesis 1. Prospector business strategies are more positively associated with knowledge-transfer $M \& A$ than Defenders business strategies.

\section{Business strategy and innovation level}

If business strategies vary in likelihood of engaging knowledge-transfer M\&A, we expect different companies have different innovation level based on their business strategies.

The prospectors are usually innovative enterprises which are more radical. They have great enthusiasm for the introduction of new knowledge, and for the development of new products and new markets(Miles and Snow ${ }^{[1-2]}$ 1978, 2003). Committed to discovering and excavating new products and new market opportunities, the prospectors, with core capability of market capabilities and R\&D capabilities, are adventurous and can provide innovative products (Walker et al. ${ }^{[13]}, 2003$; Shortell ${ }^{[14]}$, 1990). They may have more technology types and longer product lines (Laugen $^{[15]}$, 2010). Therefore, companies adopting prospector business strategy focus on new technologies or services, which inevitably leads to radical innovations that help them to grasp new opportunities in the market. So, prospectors may be more innovative than defenders and they are more willing to do radical innovations, such as knowledge-transfer M\&As.

In contrast, the defenders are relatively conservative enterprises, and do not tend to take risks to invest in financing (Rajagopalan ${ }^{[16]}$,1997; Wang Huacheng et al.,2016). Prospectors quickly transform the market portfolio of their products into innovative leaders in many areas, while defenders compete on the basis of price, service, or quality to maintain their position in the narrow and stable market (Miles and Snow ${ }^{[1-2]} 1978$, 2003). Defenders are more willing to improve their internal production efficiency and reduce costs. They are more cautious about innovative corporate behaviors, so they may not be willing to conduct knowledgetransfer M\&As.

In our study, we suggest that prospectors are more likely to do knowledge-transfer M\&As than defenders in Hypothesis 1. If it is true, prospectors will have more opportunities to get knowledge and patents from acquired companies. Then, prospectors' innovation level is expected to be higher than defenders'. Stated formally:

Hypothesis 2. Prospector business strategies are more positively associated with innovation level than Defenders business strategies.

\section{Business strategy, innovation level and knowledge-transfer M\&A}

If business strategies vary in their level of innovation and likelihood of engaging knowledge-transfer M\&A, we expect companies with higher innovation level to be more willing to conduct a knowledge-transfer M\&A. We hope to find a mediating variable between knowledge-transfer M\&A and business strategy to directly influence knowledge-transfer M\&A. If innovation level is associated with knowledge-transfer M\&A, it is probably the mediator variable of enterprise strategy's influence on knowledge transfer M\&A.

Based on the M\&A data of listed companies from 2011 to 2016 in China, Zhang et al. ${ }^{[17]}$ (2017) use calendar time portfolio method and multiple regression model to examine the impact of innovation on acquisition performance. They find the innovation level will influence acquisition performance. Han ${ }^{[18]}(2017)$ summarized the research on the relationship between BTK M\&A and innovation level within and without China and found that although both Chinese and Western studies have shown that acquiring technical resources and improving innovation ability are the main motives for BTK M\&A. Noticeably, Chinese research almost all confirm that technology M\&A promoted 
innovation, compared with the "paradox of technology M\&A effect" --the negative effect of BTK M\&A-- that frequently mentioned in Western research. Seru ${ }^{[19]}$ (2014) believed that this may be because BTK M\&As are inherent in enterprise innovation, and the level of enterprise innovation may affect the BTK M\&As. Thus, we expect that innovation level is associated with knowledge-transfer M\&A. The hypothesis 3 is as follows:

Hypothesis 3. Business strategies influence knowledgetransfer M\&A by taking innovation level as a mediator variable.

\section{Measures and models}

\section{Business strategy composite measure}

According to the theory of Miles and Snow ${ }^{[1-2]}$ (1978, 2003), Bentley ${ }^{[3]}$ (2013) constructed a discrete strategic combination model to represent the company's business strategy. This model assigns different scores to different companies based on the ranking of the company's six financial indicators within their respective industries. The company that has obtained a higher strategic score is a prospector, while company with relatively low strategic score is defined as defender. Similar to the models mentioned by Ittner ${ }^{[4]}$ (1997) and Bentley ${ }^{[3]}$ (2013), this paper uses the following six indicators as proxy variables to measure a company's strategy for two reasons. Firstly, Bentley's strategic scoring has been applied to many researches of enterprise strategy [8][25][20][21]. Ittner ${ }^{[4]}$ (1997) use four indicators to measure business strategy, namely RDS, EMPS, REV and the number of new product or service introductions. Bentley selected the identical first three indicators but exclude the last one which requires access to a proprietary database. Bentley also include three other indicators - MS, EMPF, CI - into the strategy composite measure which Hambrick ${ }^{[22]}(1983)$ and Miles and Snow ${ }^{[1-2]}(1978,2003)$ found empirically differentiates prospectors from defenders.

We select the Miles and Snow classification and Bentley's strategic scoring for two reasons. Firstly, Miles and Snow classification can be operationalized using archival data of listed companies and Bentley's strategic scoring can be used to quantize company strategy. Secondly and more importantly, the research paradigm of the big data era requires a large amount of data support the research conclusions. Bentley's strategic scoring requires only publicly available information and is generalizable across industries (the data for strategic scoring in this paper is collected from the database CSMAR). It provides a solution for the large-scale research on corporate strategic measurement in the field of finance. This classification method makes it possible to conduct strategic evaluations of hundreds and even thousands of enterprises by bulk downloading financial data of listed companies from financial databases and conduct other research related to corporate strategy.

The specific ranking methods and scoring criteria for each indicator are as follows:

(1) RDS: R\&D-Sales ratio, the ratio of $R \& D$ expenditure to sales revenue. It shows the tendency of companies to develop or obtain new products and new markets. Prospectors are more willing to divide a lot of R\&D expenditures into innovation activities than defensive ones, and similarly, the possibility of their choosing knowledge-transfer M\&A is greater. The RDS in each industry is ranked into five groups from the largest to the smallest. With the largest group scoring 5, the second largest group scoring 4, and so on.

(2) EMPS: Employee Productivity, ratio of employees to sales. Defenders pay more attention to efficiency than prospectors, so the number of employees will be as few as possible if not compromising efficiency. EMPS is measured by the ratio of employees to sales revenue. The EMPS in each industry are ranked into five groups from the largest to the smallest. The largest group scored 5 , the second largest group scored 4, and so on.

(3) REV: The historic growth rate of the company (the degree of change in the percentage of total sales per year). Defenders are not likely to create breakthroughs in total sales as the Prospectors. So, companies with high growth rates are more likely to be a prospector that deserves higher scores. The REVs in each industry are divided into five groups and ranked in descending order and. The largest group gets a score of 5, the second largest group gets score of 4 , and so on.

(4) MS: Market ratio, the degree of the company's concentration focusing on new products and new markets, represented as the ratio of sales expenses and management expenses to sales revenue. Prospectors will be more inclined to invest more in maintaining customer relationships. Therefore, the greater the proportion of sales expenses and management expenses in sales revenue, the more likely it is a prospector that should be given higher points. The MSs in each industry are ranked in descending order and divided into five groups. The largest group has a score of 5, the second largest group has a score of 4 , and so on.

(5) EMPF: The stability of organization, specifically represented by staff fluctuations (standard deviation of total employees, the larger the value is, the more unstable). Prospectors are far less stable than defensive ones. Prospectors' employees have shorter employment periods and higher frequency of personnel replacement, so the organizations are more unstable. The standard 
deviation of the total number of employees is used to indicate organizational stability. The larger the standard deviation is, the more unstable it is, and the more likely it is to be a prospector with higher score. The EMPF within each industry is ranked into five groups from the largest to the smallest, with the largest group scoring 5, the second largest group scoring 4, and so on.

(6) CI: Capital intensity, ratio of net fixed assets to total assets. Defenders are more inclined to increase productivity and invest in production assets. So the greater the capital density, the more likely it is to be defensive, and the lower the score should be. The CIs of each company are ranked in their industry from the smallest to the largest and divided into five groups. The smallest group has a score of 5 , the second smallest group has a score of 4 , and so on.

We assign all indicators of each company score from 1 to 5 in the industry ranking, and the six indicators of each company are scored after the ranking. We take the average of each indicators of five years, which not only ref er to the financial indicator data of that year but also two years before and after. After the ranking in each industry, the six indicators are assigned points based on the quintile they are in. The scores for the highest quintile score segment are 5 points, the scores for the second highest quintile segment are 4 points, and so on, and the score for these indicators in the lowest quintile score segment is 1 point. For each company, we add up all the six variables with a possible maximum score of 30 (prospector) and a minimum score of 6 (defender). According to the classification of company strategy by Bentley ${ }^{[3]}$ (2013), Miles and Snow ${ }^{[1-2]}(1978,2003)$,

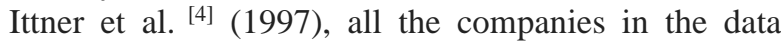
sample are divided into three categories according to their scores:

Defenders (6-12), Analyzers (13-23), and Prospectors (24-30).

\section{Innovation level measure}

Scholars of management and finance generally think that the number of patents should be used as a measure of innovation level or innovation performance. Since the 1920 s, patents have been widely used by academics as an effective measure of innovation capability and technological innovation level of a company. (Scherer $^{[23]}$, 1965; Hall, Griliches \& Hausman ${ }^{[24]}$, 1986; Scherer $^{[25]}$, 1983; Acs \& Audretsch ${ }^{[26]}$, 1989). Most Chinese scholars have adopted the number of patents as indicators for measuring the level of company innovation when they are studying the level of corporate innovation and innovation performance. The number of patents is a strong correlation indicator that reflects the company's innovation capability and R\&D investment (Pan Donghua and Sun Chen ${ }^{[27]}$, 2013; Zhang Jie ${ }^{[28]}$,
2016). Thus, we take the patent grants of enterprises in the next year after M\&A as the proxy variable of enterprises' innovation level.

\section{Mediating effect model}

We use logistic regression and multiple linear regression to construct a mediating effect model to determine whether business strategy is associated with knowledge-transfer M\&A by taking innovation level as a mediator variable. We use logistic regression to determine whether business strategy is associated with knowledgetransfer M\&A.

We select logistic regression to conduct the empirical analysis mainly because the dependent variable, $\mathrm{KT}$, is a $0-1$ variable and the data is subjected to logical distribution.

The model for the likelihood of knowledgetransfer M\&A is as follows:

$$
\begin{gathered}
K T=\alpha+\beta_{1} \text { Strategy }+\beta_{2} \text { Size }+\beta_{3} \text { Leverag } \\
+\beta_{4} \text { Cashflow }+\beta_{5} C R+\beta_{6} I B R+\varepsilon \\
\text { Model (1) }
\end{gathered}
$$

Economists tend to assume the standard normal distribution of dependent variable when they make an empirical analysis based on panel data. We assume the dependent variable, Patent, is a standard normal random variable, so we use multiple linear regression to determine whether business strategy is associated with innovation level. The model for the likelihood of innovation level (Patent is the proxy variable of innovation level) is as follows:

$$
\begin{aligned}
\text { Patent }=\alpha & +\delta_{1} \text { strategy }+\beta_{2} \text { Pattern }+\beta_{3} \text { Size } \\
& +\beta_{4} \text { Leverage }+\beta_{5} \text { Cashflow }+\beta_{6} C \\
& +\beta_{7} I B R+\varepsilon \\
& \text { Model }(2)
\end{aligned}
$$

We use logistic regression to determine whether innovation level is associated with knowledgetransfer M\&A. The model for the likelihood of knowledge-transfer M\&A is as follows:

$$
\begin{aligned}
K T= & \alpha+\delta_{2} \text { Patent }+\beta_{2} \text { Pattern }+\beta_{3} \text { Size } \\
& +\beta_{4} \text { Leverage }+\beta_{5} \text { Cashflow }+\beta_{6} C R \\
& +\beta_{7} \text { IBR }+\varepsilon
\end{aligned}
$$

Using the Causal Steps App Roach proposed by Baron and Kenney ${ }^{[29]}$ (1986) and the Product of Coefficients Approach proposed by Sobel ${ }^{[30]}$ (1982), this paper further examines whether the impact of strategic orientation on knowledge-transfer M\&A is based on the mediator variable-innovation level. Sun 
Jian (2016) ${ }^{[31]}$ used Sobel's method to test the strategy's effect on earnings management through the mediating effect of financing requirements. Similar to its model design, this paper designs models (2) and (3) to test the relationship between company strategy, knowledgetransfer M\&A and the level of innovation. Model (1) examines whether prospector business strategy have an impact on the knowledge-transfer M\&A. We expect there will be a positive correlation between prospector business strategy and knowledge-transfer merger and acquisition. If it is true, $\beta_{1} \neq 0$. Model (2) examines whether prospector business strategy have an impact on the innovation level. We expect there will be a positive correlation between prospector business strategy and innovation level. If it is true, $\delta_{1} \neq 0$. Model (3) examines whether innovation levels have an impact on knowledge-transfer M\&A. We expect there will be a positive correlation between innovation levels and knowledge-transfer M\&A. If it is true, $\delta_{2} \neq 0$. If $\delta_{1} *$ $\delta_{2} \neq 0$, the mediating effect is significant. The level of innovation in model (2) is the dependent variable, and Patent (the number of patent grants) is the proxy variable of the dependent variable. Strategy (prospector business strategy) is the independent variable, and the control variable is the same as the model (1). The specific explanation is shown in Table 1. Multiple linear regression is used to test whether $\delta_{1}$ is above 0 . In model (3), KT is the independent variable, while Patent is the

Table 1 Variable descriptions

\begin{tabular}{|c|c|}
\hline Variable & Description \\
\hline KT & $\begin{array}{l}\text { Knowledge transfer M\&A; KT } \\
\text { equal to } 1 \text { if M\&A is an } \\
\text { knowledge-transfer M\&A } \\
\text { event, otherwise } 0 .\end{array}$ \\
\hline Strategy & $\begin{array}{l}\text { Prospector business strategy; } \\
\text { Strategy Equal to } 1 \text { when it is a } \\
\text { prospector business strategy, } \\
\text { otherwise } 0 \text {. }\end{array}$ \\
\hline Patent & $\begin{array}{l}\text { Patent is the proxy variable of } \\
\text { innovation level }\end{array}$ \\
\hline Pattern & $\begin{array}{l}\text { Nature of property right. } \\
\text { Pattern takes value of } 1 \text { for } \\
\text { state-owned company and } 0 \text { for } \\
\text { non-state-owned company. }\end{array}$ \\
\hline Size & $\begin{array}{l}\text { Company size, expressed as the } \\
\text { natural logarithm of total assets. }\end{array}$ \\
\hline Leverage & Assets-liability ratio \\
\hline Cashflow & $\begin{array}{l}\text { Net cash flow from business } \\
\text { activities }\end{array}$ \\
\hline $\mathrm{CR}$ & Current ratio \\
\hline IBR & $\begin{array}{l}\text { Increasing rate of business } \\
\text { revenue }\end{array}$ \\
\hline
\end{tabular}

\section{Data}

dependent variable, and other variables are the same as model (1). The specific explanation is shown in Table 2. As $\mathrm{KT}$ is a $0-1$ variable, we use the Probit model to perform logistic regression and test whether $\delta_{2}$ is 0 or not. We put the mediator variable Patent into the model (1) to generate a new model (4) and do a logistic regression through the Probit model. The model(4) is as follows:

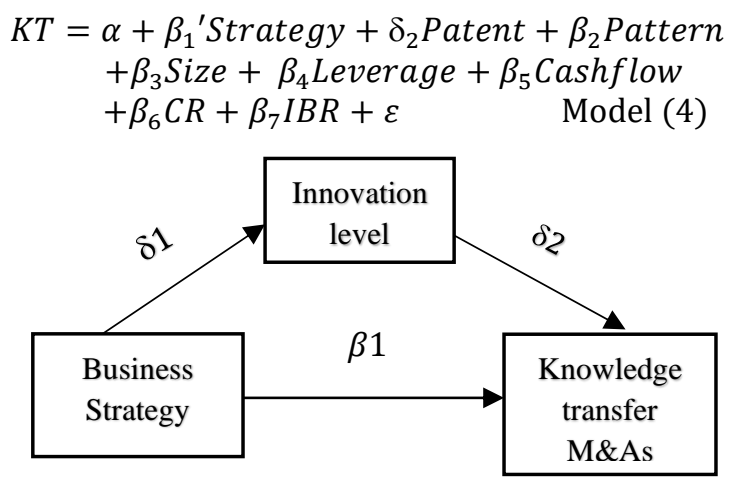

Figure 1. Mediating effect model

We use Model (1), Model (2) and Model (3) to construct the mediating effect model. Schematic diagram of mediating effect is shown in Figure 1. All variables in our models are defined in Table 1.

\section{Data collection}

This paper selects M\&A events in all industries from 2011 to 2016 as data samples and conducts regression analysis on data samples.

The reason why we select M\&A events from 2011 to 2016 is as follows: The valid evaluation of enterprise strategy in a certain year should not only refer to the financial indicator data of that year but also two years before and after, that is the rolling average of five years' data. Since the latest accessible data by now is 2018, accordingly the latest year we can analyze is 2016 . To make the analysis more credible, we also include the other four years previous to 2016 in our research. Therefore, based on the latest available financial indicators data from 2009 to 2018, we analyze the business strategy of the M\&A event from 2011 to 2016.

A total number of 2,869 M\&A data is collected from the database CSMAR. Each piece of data is an M\&A event that accompanied with the main acquiring company's stock code, the time of the M\&A announcement, the payment method, and the six financial indicators for scoring strategies. The industry classification of all companies is based on the 2012 edition industry classification released by China 
Securities Regulatory Commission. The specific approach to distinguish the type of M\&A is to read through the M\&A announcement of the main acquiring company and focus on the M\&A purposes and its influence, determining whether the acquisition is to obtain new technologies, new products, open new markets and whether it has had an innovative impact. After clarifying the type of each M\&A data, the knowledge-transfer M\&A are marked.

\section{Table 2 Industries statistics}

\begin{tabular}{lc}
\hline \multicolumn{1}{c}{ Industry } & Number of companies \\
\hline $\begin{array}{l}\text { Mining } \\
\begin{array}{l}\text { Electricity, heat gas and } \\
\text { water production and supply }\end{array}\end{array}$ & 94 \\
Real estate & 144 \\
$\begin{array}{l}\text { Construction } \\
\text { Transportation, warehousing } \\
\text { and postal services }\end{array}$ & 81 \\
$\begin{array}{l}\text { Education } \\
\text { Finance }\end{array}$ & 81 \\
$\begin{array}{l}\text { Resident Service, repairs } \\
\text { and other services }\end{array}$ & 1 \\
$\begin{array}{l}\text { Scientific research and } \\
\text { technology service } \\
\begin{array}{l}\text { Agriculture, forestry, animal } \\
\text { husbandry and fishery }\end{array}\end{array}$ & 61
\end{tabular}

We invited 20 students majored in accounting to read the announcement text of M\&A and made a statistic of the number of knowledge-transfer M\&As. Then we show the result in Table 3: about $37.3 \%$ of the acquiring companies are aiming to obtain knowledge or technologies in M\&As. Such merger and acquisition are knowledge-transfer M\&As.

\section{Table 3 knowledge-transfer M\&A statistic}

\begin{tabular}{ccc}
\hline Total Number & $\begin{array}{l}\text { Knowledge } \\
\text { transfer M\&A }\end{array}$ & $\begin{array}{l}\text { Non-knowledge } \\
\text { transfer M\&A }\end{array}$ \\
\hline 2726 & 1017 & 1709 \\
\hline
\end{tabular}

After scoring according to the strategy scoring method, 6-12 points are classified as defenders, 13-23 are classified as analytical companies, and 24-30 are classified as prospectors. After eliminating enterprises with incomplete data, the types of all acquirers (acquiring companies) are in the Table 4.

Table 4 Business strategies statistic

\begin{tabular}{cccc} 
Strategy & Prospector & Defender & Analyzer \\
\hline Number & 125 & 147 & 2597 \\
\hline
\end{tabular}

\section{Descriptive statistics}

The statistics of sample data according to industry classification are shown in Table 2 . The industry most keen on mergers and acquisitions is Manufacturing and there were 1657 companies in this industry having made M\&A in 2011 to 2016. Education and Resident Service, repairs and other services are not keen on M\&A because only one company in these two industries has made a M\&A.

\begin{tabular}{lc} 
Wholesale and retail trade & 156 \\
Water conservancy, & \\
environment and public & \\
facilities Management & \\
$\begin{array}{l}\text { Health and social work } \\
\text { Culture, sports and } \\
\text { entertainment }\end{array}$ & 5 \\
$\begin{array}{l}\text { Information transmission, } \\
\text { software and information }\end{array}$ & 69 \\
$\begin{array}{l}\text { Technology service } \\
\text { Manufacturing }\end{array}$ & 260 \\
$\begin{array}{l}\text { Accommodation and } \\
\text { catering }\end{array}$ & 1657 \\
Synthesis & 9 \\
Leasing and business service & 17 \\
\hline Total & 40 \\
\hline
\end{tabular}

According to the statistics of different types of companies, there are 125 prospectors, 147 defenders, and 2,597 analytical companies. We find that the number of prospectors and defenders are similar to each other and the number of analyzers is much larger than both prospectors and defenders. This paper mainly conducts regression analysis on the data of Prospectors and defenders and there is a total of 223 samples after eliminating dates with missing variables.

\section{Correlation analysis}

In order to prove the reasonability of the setting of control variables, a correlation analysis is made among the dependent variable, independent variable and control variables before the regression analysis. It can be seen in the table 5 that the correlation between the control variables and the dependent variable is very weak. Except that the correlation coefficient between Leverage and dependent variable KT (knowledgetransfer M\&A) is -0.3444 , the absolute values of 
correlation coefficient between other control variables and dependent variable KT are all below 0.3 , indicating that there is no collinearity between the control variables and the dependent variable. The absolute values of the correlation coefficient between the control variable and the independent variable Strategy are all less than 0.3, and some are even less than 0.1 , which shows that there is no collinearity between the control variables and the independent variable either. Therefore, it is considered that the degree of correlation between these control variables and independent variable does not affect the significance of the regression results.

Table 6 Correlation coefficient

\begin{tabular}{|c|c|c|c|c|c|c|c|}
\hline Variable & KT & Strategy & Size & Leverage & Cashflow & $\mathrm{CR}$ & IBR \\
\hline KT & 1.0000 & & & & & & \\
\hline Strategy & $0.1965^{* * *}$ & 1.0000 & & & & & \\
\hline Size & $-0.2107^{* * *}$ & $0.2690^{* * * *}$ & 1.0000 & & & & \\
\hline Leverage & $-0.3444^{* * * *}$ & $-0.2967^{* * *}$ & $0.2320^{* * *}$ & 1.0000 & & & \\
\hline Cashflow & $0.1116^{*}$ & -0.0012 & 0.0222 & -0.0996 & 1.0000 & & \\
\hline $\mathrm{CR}$ & $0.2009^{* * * *}$ & $0.1777^{* * * *}$ & -0.1072 & $-0.5478^{* * *}$ & -0.0272 & 1.0000 & \\
\hline IBR & -0.0650 & $0.1373^{* *}$ & $0.2306^{* * *}$ & -0.0038 & $0.1476^{* *}$ & $-0.1423^{* *}$ & 1.0000 \\
\hline
\end{tabular}

\section{Result}

The regression results in Table 7 shows that the independent variable Strategy (whether it is a prospector or not) has significant influence on the dependent variable KT (whether it is a knowledge transfer merger or not) and the two variables show positive correlation. This paper uses the dprobit command to calculate the marginal influence of the independent variable on the dependent variable. The change rate of 0.2039 can be understood as that when the acquirer is a prospector, the probability of a knowledge-transfer M\&A event is $20.39 \%$ higher than that when the acquirer is a defender. Therefore, prospectors are more likely to conduct knowledge-transfer M\&A than defenders, consistent with Hypothesis 1.

Table 7 Business strategy and KT model estimation

\begin{tabular}{ccc}
\hline \multirow{2}{*}{ Independent variable } & \multicolumn{2}{c}{ Dependent variable KT } \\
\cline { 2 - 3 } & $\begin{array}{c}\text { Rate of change } \\
\text { dx/df }\end{array}$ & P-value \\
\hline Strategy & $0.2039^{* * *}$ & 0.010 \\
Size & $-0.0872^{* *}$ & 0.011 \\
Leverage & $-0.4420^{* *}$ & 0.015 \\
Cashflow & $0.8434^{*}$ & 0.096 \\
CR & -0.0006 & 0.930 \\
IBR & -0.1241 & 0.329 \\
\hline Pseudo R & \multicolumn{2}{c}{0.1403} \\
$\mathrm{n}$ & \multicolumn{2}{c}{223}
\end{tabular}

\begin{tabular}{cc}
$\mathrm{LR} \mathrm{chi}^{2}(6)$ & 41.45 \\
Prob>chi & 0.0000 \\
\hline Notes: ${ }^{* * *},{ }^{* *},{ }^{*}$ signify that the statistical test \\
are significant at the $1 \%, 5 \%$, and $10 \%$.
\end{tabular}

Table 8 Business strategy and innovation level model estimation

Dependent variable innovation

\begin{tabular}{|c|c|c|}
\hline \multirow{2}{*}{ Independent variable } & \multicolumn{2}{|c|}{ level (Patent) } \\
\hline & $\begin{array}{l}\text { Regression } \\
\text { coefficient }\end{array}$ & P-value \\
\hline Strategy & $85.9697 * * *$ & 0.000 \\
\hline Size & $13.0396^{* *}$ & 0.043 \\
\hline Leverage & 32.6086 & 0.322 \\
\hline Cashflow & 152.5638 & 0.188 \\
\hline $\mathrm{CR}$ & -1.4092 & 0.261 \\
\hline IBR & -19.1461 & 0.389 \\
\hline R-squared & \multicolumn{2}{|c|}{0.1934} \\
\hline $\mathrm{n}$ & \multicolumn{2}{|c|}{223} \\
\hline Prob $>F$ & \multicolumn{2}{|c|}{0.0000} \\
\hline
\end{tabular}

According to the regression results shown in Table 8 and Table $9, \delta_{1}=85.9697, \delta_{2}=0.0005$, so $\delta_{1} * \delta_{2} \neq$ 0 . The regression results of model (4) are shown in Table 10, resulting in $\beta_{1}{ }^{\prime}=0.1773 \mathrm{p}=0.035$. Compared 
to the $\beta_{1}=0.19 p=0.013$ in model (1) that did not include the mediator variable, the model's coefficient became smaller and the significance level decreased after adding the mediator patent. According to Baron and Kenney's ${ }^{[18]}$ (1986) step-by-step test of the mediating effect, this paper concludes that the mediating effect of strategy based on innovation level influences knowledge-transfer M\&A. The mediating effect is significant.

\section{Table 9 Innovation level and KT model estimation}

\begin{tabular}{|c|c|c|}
\hline \multirow[b]{2}{*}{ Independent variable } & \multicolumn{2}{|c|}{ Dependent variable KT } \\
\hline & $\begin{array}{l}\text { Rate of change } \\
\mathrm{dx} / \mathrm{df}\end{array}$ & P-value \\
\hline Patent & $0.0005^{*}$ & 0.093 \\
\hline Size & $-0.0736 * *$ & 0.028 \\
\hline Leverage & $-0.598 * * *$ & 0.000 \\
\hline Cashflow & 0.5612 & 0.252 \\
\hline CR & -0.0000 & 0.994 \\
\hline IBR & -0.0827 & 0.499 \\
\hline Pseudo $\mathrm{R}^{2}$ & \multicolumn{2}{|c|}{0.1282} \\
\hline $\mathrm{n}$ & \multicolumn{2}{|c|}{223} \\
\hline (6) & \multicolumn{2}{|c|}{37.89} \\
\hline Prob $>$ chi 2 & \multicolumn{2}{|c|}{0.0000} \\
\hline \multicolumn{3}{|c|}{$\begin{array}{c}\text { Notes: }{ }^{* * *},{ }^{* *},{ }^{*} \text { signify that the statistical test } \\
\text { are significant at the } 1 \%, 5 \% \text {, and } 10 \% \text {. }\end{array}$} \\
\hline \multicolumn{3}{|c|}{$\begin{array}{c}\text { Table } 10 \text { Business strategy, innovation } \\
\text { level and KT model estimation }\end{array}$} \\
\hline \multirow[b]{2}{*}{ Independent variable } & \multicolumn{2}{|c|}{ Dependent variable KT } \\
\hline & $\begin{array}{l}\text { Rate of change } \\
\text { dx/df }\end{array}$ & P-value \\
\hline Strategy & $0.1773 * *$ & 0.035 \\
\hline Patent & 0.0003 & 0.360 \\
\hline Size & $-0.0912 * * *$ & 0.008 \\
\hline Leverage & $-0.4584^{* *}$ & 0.012 \\
\hline Cashflow & 0.8061 & 0.113 \\
\hline $\mathrm{CR}$ & -0.0003 & 0.962 \\
\hline IBR & -0.1231 & 0.335 \\
\hline Pseudo $\mathrm{R}^{2}$ & \multicolumn{2}{|c|}{0.1435} \\
\hline $\mathrm{n}$ & \multicolumn{2}{|c|}{223} \\
\hline LR chi2 (7) & \multicolumn{2}{|c|}{42.40} \\
\hline Prob>chi2 & \multicolumn{2}{|c|}{0.0000} \\
\hline
\end{tabular}

\section{Conclusion}

This paper studies the relationship between business strategy and knowledge-transfer M\&A. Taking the 2,726 M\&A events that occurred in 2011-2016 as research samples, the M\&A events of prospectors and defenders were extracted through strategic scoring, and 223 companies were regression-analyzed after eliminating the missing data. The following three conclusions were reached: Firstly, companies that adopt prospector business strategies are more inclined to taking knowledge-transfer M\&A than those that adopt defender business strategies, which is consistent with prior research (Miles and Snow ${ }^{[1-2]}$ 1978, 2003, Bentley ${ }^{[3]}, 2013$, Wang Huacheng et al. ${ }^{[11]}, 2016$ ) that prospectors are usually innovative enterprises which are more radical while defenders are more cautious about innovative behaviors; Secondly, business strategies are associated with innovation level and prospectors are more likely to have a higher innovation level; Thirdly, the business strategy influences knowledge-transfer M\&A through the mediator variable innovation level.

The contribution of this paper is reflected in the following two aspects: Firstly, we provide evidence that differences in the choice of business strategies is an underlying determinant of the likelihood of knowledgetransfer M\&As and innovation level. Secondly, we construct a comprehensive, theory-based mediating effect model of business strategy, innovation level and knowledge-transfer M\&As which reveals the internal relationship among them. It broadens the application of corporate strategy in accounting research.

Our research is subject to two limitations. Although we explored that business strategies have direct influence on knowledge-transfer knowledge-transfer M\&A by the mediator variable innovation level, the rate of change of innovation level on M\&A is relatively low. It is too simple to use only the number of patents as a proxy variable for the level of innovation. A composite measure of innovation level should be constructed. Another limitation is that we assess the type of M\&A with noise because we rely on manual reading and screening of the M\&A announcement text to distinguish the types of M\&As. To some extent that reading error could lead to misclassifying some M\&As' types.

There are some new directions for future researches based on this paper. One is to explore other mediator variables of business strategies' influence on knowledge-transfer M\&As since the innovation level's influence on M\&As showed in this paper is not very significant. The other is to examine whether the companies will benefit from knowledge-transfer M\&As when they apply prospector business strategies.

\section{Acknowledgement}


This research is funded by the National Social Science Found Major Project of China (18ZDA325), the National Social Science Found Project of China (16BTQ055) and the Fundamental Research Funds for the Central Universities (H\&S Independent Research Projects of Wuhan University).

\section{References}

[1] Miles, R. E., et al., "Organizational Strategy, Structure, and Process.", Academy of Management Review, 1978, 3(3), pp. 546-562.

[2] Miles, R. E., and C. C. Snow, "Organizational strategy, structure, and process., Stanford.”, CA: Stanford University Press, 2003.

[3] Bentley, Kathleen A., T. C. Omer, and N. Y. Sharp, "Business Strategy, Financial Reporting Irregularities, and Audit Effort.", Contemporary Accounting Research, 2013, 30(2), pp. 780-817.

[4] Autio, E, and T. Laamanen, "Measurement and evaluation of technology transfer: review of technology transfer mechanisms and indicators.", International Journal of Technology Management, 1995, pp. 643-664.

[5] Bresman, H., Birkinshaw, J.\& Nobel, R., "Knowledge transfer in international acquisitions.", Journal of International Business Studies, 1999, 30, pp.439-462.

[6] Andreas Ring et al., "Contextualized view of knowledge transfer in mergers and acquisitions-a case study of knowledge intensive companies.", International Management Master Thesis, 2000.

[7] Granstrand O, Bohlin E, Oskarsson C, et al., "External technology acquisition in large multi-technology corporation.”, R\&D Management, 2010, 22(2), pp.111-113.

[8] Bena J, Li K., "Corporate Innovations and Mergers and Acquisitions.”, Journal of Finance, 2014, 69(5), pp.1923-1960. [9] Ahuja, Gautam, and R. Katila., "Technological Acquisitions and the Innovation Performance of Acquiring Firms: A Longitudinal Study.", Strategic Management Journal, 2001, 22(3), pp. 197-220.

[10] Song, Michael, C. A. D. Benedetto, and R. W. Nason, "Capabilities and financial performance: the moderating effect of strategic type?", Journal of the Academy of Marketing Science, 2007, 35(1), pp. 18-34.

[11] Huacheng, Wang, et al., "Does Corporate Strategy Influence Overinvestment?", Nankai Business Review, 2016, 4, pp. 87-97.(In China)

[12] Agrawal A, Jaffe J F, Mandelker G N., "The Post-Merger Performance of Acquiring Firms: A Re-examination of an Anomaly.", The Journal of Finance, 1992, 47(4), pp. 16051621.

[13] Jr. Walker, O.C., Boyd, H.W., Jr. Mullins, J., et al., "Marketing strategy: Planning and implementation.", Irwin Professional Publishing, 2003.

[14] Shortell S M, Zajac E J. Perceptual and Archival, "Measures of Miles and Snow's Strategic Types: A
Comprehensive Assessment of Reliability and Validity.", Academy of Management Journal, 1990, 33(4), pp. 817-832. [15] Laugen, Bjorge Timenes, H. Boer, and N. Acur, "The New Product Development Improvement Motives and Practices of Miles and Snow's Prospectors, Analyzers and Defenders.", Creativity \& Innovation Management, 2006, 15(1), pp.85-95.

[16] Rajagopalan N., "Strategic Orientations, Incentive Plan Adoptions, and Firm Performance: Evidence from Electric Utility Firms.”, Strategic Management Journal, 1997, 18(10), pp. 761-785.

[17] Zhang Xueyong et al., "The Impact of Innovation on Acquisition Performance.", Journal of Financial Research, 2017(03), pp.159-175. (In China)

[18] Han Baoshan. "Technology Acquisitions and Innovation: A Review and Research Prospect.”, Business Management Journal, 2017, 39(09), pp.195-208. (In China)

[19] Seru A., "Firm boundaries matter: Evidence from conglomerates and R\&D activity.", Social Science Electronic Publishing, 2014, 111(2):381-405.

[20] Higgins D, Omer T C, Phillips J D., "The Influence of a Firm's Business Strategy on its Tax Aggressiveness.", Contemporary Accounting Research, 2015, 32(2), pp. 674702.

[21] Wang Yutao et al., "Does Business Strategy Impact a Firm's Management Earnings Forecasts?" Management Review, 2019, 31(02), pp.200-213. (In China)

[22] Hambrick, D. C., "Some tests of the effectiveness and functional attributes of Miles and Snow's strategic types.", The Academy of Management Journal 1983, 26 (1), pp.5-26. [23] Scherer, Frederick M., "Firm Size, Market Structure, Opportunity, and the Output of Patented Inventions.", American Economic Review, 1965, 55(5), pp. 1097-1125.

[24] Hall, Bronwyn H., Z. Griliches, and J. A. Hausman, "Patents and R and D: Is There a Lag?", International Economic Review, 1986, 27(2), pp. 265-283.

[25] Scherer, F. M., “The propensity to patent.”, International Journal of Industrial Organization, 1983, 1(1), pp. 107-128.

[26] Acs Z J, Audretsch D B., "Patents as a Measure of Innovative Activity.”, Kyklos, 1989, 42(2), pp. 171-180.

[27] Donghua, Pan, and S. Chen, "Innovation performance evaluation of industry technology innovation strategic alliance.", Science Research Management, 2013, 34(1), pp. 296-301. (In China)

[28] Jie, Zhang, G. De-Bu, and X. Yan-Lei, "Do Patents Drive Economic Growth in China-An Explanation Based on Government Patent Subsidy Policy.", China Industrial Economics, 2016, 1, pp. 83-98. (In China)

[29] Baron, R. M., \& Kenny, D. A., "The moderator-mediator variable distinction in social psychological research: Conceptual, strategic and statistical considerations, Journal of Personality and Social Psychology.”, 1986, 51(6), pp. 11731182.

[30] Sobel, Michael E., "Asymptotic Confidence Intervals for Indirect Effects in Structural Equation Models.", Sociological Methodology, 1982, 13, pp. 290-312.

[31] Sun J, Wang B Q, Cao F, etc. "Does the company's strategy affect earnings management?" Management World, 2016, 270(3), pp. 160-169. (In China) 